\title{
Vitamin D and Its Role in Neonatal Hypoxic-Ischemic Brain Injury
}

\author{
Lyndsey E. Stessman Eric S. Peeples \\ Department of Pediatrics, University of Nebraska Medical Center, Omaha, NE, USA
}

\section{Keywords}

Asphyxia - Cholecalciferol - Deficiency - Development .

Ergocalciferol · Hydroxyvitamin D · Neurohormone

\begin{abstract}
s
Emerging evidence has demonstrated that vitamin D plays an important role in many adult neurologic disorders, but is also critical in neuronal development and pruning in the neonatal and pediatric populations. Neonates are at a particularly high risk of vitamin D deficiency, in part due to the high prevalence of maternal deficiency during pregnancy. Several preclinical studies have demonstrated that infants born to vitamin D-deficient mothers are at a high risk of developing neonatal brain injury, and recent clinical studies have shown that neonates with hypoxic-ischemic encephalopathy (HIE) tend to be vitamin D-deficient. There are limited data, however, on whether additional prenatal or postnatal supplementation may alter the prevalence or severity of neonatal HIE. This review examines the current data supporting the neuroprotective role of vitamin $D$, with a focus on how these findings may be translated to neonates with HIE.
\end{abstract}

(c) 2018 S. Karger AG, Basel

\section{KARGER}

(C) 2018 S. Karger AG, Basel

E-Mail karger@karger.com

www.karger.com/neo

\section{Introduction}

Vitamin D is a hormone that affects a wide range of functions within the body. It has traditionally been associated with calcium and bone metabolism, but more recently has been demonstrated to be a vital component in neuronal development and dysfunction. In North America, $61 \%$ of children are vitamin D insufficient and $9 \%$ are deficient, commonly defined as $50-80 \mathrm{nmol} / \mathrm{L}$ and $<50$ $\mathrm{nmol} / \mathrm{L}$, respectively $[1,2]$. Neonates are at a particularly high risk of vitamin $\mathrm{D}$ deficiency, primarily due to maternal deficiency and a lack of adequate perinatal supplementation. This is supported by the observation of low cord-blood vitamin D levels at birth [3]. A recent metaanalysis estimated that $54 \%$ of pregnant women worldwide are deficient in vitamin $\mathrm{D}$ and $18 \%$ are severely deficient, correlating with rates in infants of $75 \%$ with deficiency and $29 \%$ with severe deficiency [4]. Infants born to non-white mothers are at particularly high risk of vitamin $\mathrm{D}$ deficiency, with some races demonstrating rates of deficiency during pregnancy as high as $85 \%[3,5]$.

In addition to its effect on bone mineralization, vitamin $\mathrm{D}$ is also a potent neurohormone, with vitamin $\mathrm{D}$ receptors (VDRs) and several enzymes in the vitamin D synthetic pathway found throughout the brain $[6,7]$. In addition to direct effects on VDRs, vitamin $\mathrm{D}$ also regulates calcium [8] and inflammatory cytokines [9-11]. In adults, vitamin
Eric Peeples

Children's Hospital and Medical Center 8200 Dodge Street

Omaha, NE 68114-4113 (USA)

E-Mail eric.peeples@unmc.edu 


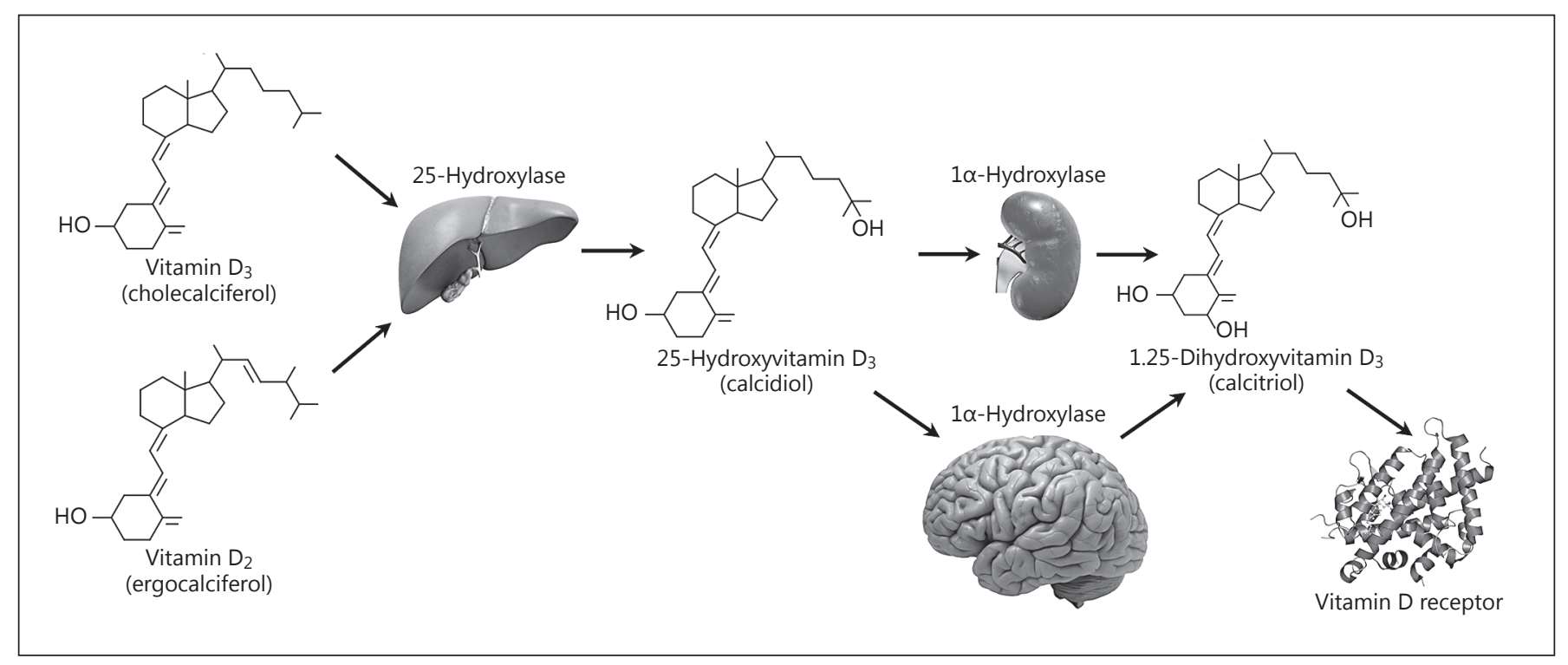

Fig. 1. Forms and metabolism of vitamin D.

D deficiency has been associated with the development and severity of ischemic stroke [9]. Studies of therapeutic vitamin D administration to improve the outcomes in adults with ischemic stroke have yet to demonstrate clear benefit. These data do not rule out a role for vitamin D in neonatal ischemic disorders, however, as animal studies of cerebral ischemia have demonstrated an increasing effect of calcitriol administration correlating with younger age [12]. During development, vitamin D influences the brain via its effects on neurotrophic factors [13-16], and animal studies have shown vitamin $\mathrm{D}$ deficiency to be a risk factor for abnormal brain development [13]. These findings suggest that vitamin D supplementation may play a significant role during the period of greatest brain growth and development: infancy and childhood.

Hypoxic-ischemic encephalopathy (HIE) is a potentially devastating neonatal brain injury with long-term neurologic effects that affects between 1 and 8/1,000 live births, with the highest rates in developing countries [17]. Given the data supporting the role of vitamin D as a protective neurohormone, investigators have begun to assess if vitamin D could play role in the prevention or therapy of neonatal HIE. Early results have demonstrated low levels of vitamin $\mathrm{D}$ in infants and the mothers of infants who have suffered from HIE [18], and the neonates' serum vitamin D levels often continue to decline for $72 \mathrm{~h}$ after the injury despite supplementation [19]. The story of the interaction between vitamin $\mathrm{D}$ and neonatal HIE has just begun to unfold, and many questions remain unanswered.
This is a critical review of the current data regarding vitamin D supplementation and the effects of vitamin D on fetal brain development, cellular damage, and apoptosis. In addition, we examine the animal and human data regarding the relationship between vitamin $\mathrm{D}$ deficiency and HIE, including the importance of the timing of supplementation with respect to the injury, and the effects on the severity of hypoxic injury.

\section{Vitamin D Supplementation in Neonates}

Vitamin D supplementation is available in several forms: vitamin $\mathrm{D}_{2}$ (ergocalciferol) and vitamin $\mathrm{D}_{3}$ (cholecalciferol), and the biologically active 1,25-dihydroxyvitamin $\mathrm{D}_{3}$ (calcitriol) (Fig. 1). Clinically, supplementation with calcitriol is not recommended because it is thought to bypass important metabolites that are created by vitamin $D_{2}$ or $D_{3}$ supplementation. Comparing the efficacy of vitamins $\mathrm{D}_{2}$ and $\mathrm{D}_{3}$ in adult studies has demonstrated that vitamin $\mathrm{D}_{3}$ supplementation leads to greater increases in 25 -hydroxy vitamin $\mathrm{D}(25(\mathrm{OH}) \mathrm{D})$ than vitamin $\mathrm{D}_{2}$, and the maintenance of higher levels in the blood longer after administration [20, 21]. In neonates, some data have suggested that vitamin $\mathrm{D}_{2}$ is absorbed better than vitamin $\mathrm{D}_{3}$ in younger neonates, with the least robust absorption occurring in the first 10 days of life, possibly due to differences in bile acid secretion [22]. When assessing therapeutic efficacy, however, a study performed on an in vitro 
model of neuronal injury demonstrated that $\mathrm{D}_{3}$ resulted in increased myelination, increased formation and diameter of new axons, and improved axonal protection from injury when compared to $D_{2}$ [23]. These findings suggest that vitamin $\mathrm{D}_{3}$ may be more effective, although a higher dose may be necessary during the first few weeks of life.

In neonates, the optimal dose for vitamin $\mathrm{D}$ supplementation remains unclear, partly because of the variation in the results of vitamin $\mathrm{D}$ studies due to maternal vitamin D status, feeding practices, and the amount of sun exposure of the study subjects. For instance, 1 study demonstrated that a dose of $250 \mathrm{IU}$ of vitamin $\mathrm{D}_{3}$ daily resulted in appropriate levels of $25(\mathrm{OH}) \mathrm{D}(116-164 \mathrm{nmol} / \mathrm{L}) \mathrm{nec}-$ essary for calcium homeostasis and healthy bone [24], while another study showed that oral vitamin $\mathrm{D}_{3}$ was unable to meet a goal of $75 \mathrm{nmol} / \mathrm{L}$ blood concentration unless 1,600 IU per day was administered [25]. Both studies were conducted on healthy, full-term, breastfed neonates, but the differences in medication formulation and duration of follow-up could have led to some of these differences in outcomes. The recommended levels of vitamin $\mathrm{D}$ are also controversial, with sources recommending minimal levels anywhere from 50 to $80 \mathrm{nmol} / \mathrm{L}$ [2, 26-28].

The dose and level of vitamin D that would potentially be necessary to provide neuroprotection is unknown. Traditional supplementation doses for bone health are likely inadequate, as there is evidence that higher levels of vitamin $\mathrm{D}$ are required for inflammatory and immune functions than for calcium homeostasis and bone development [29]. Higher doses result in a more narrow therapeutic window, however, and if high doses are used it will be vital to remain mindful of the risk of hypervitaminosis. Until more data are available, the American Academy of Pediatrics recommendation currently states that all healthy term infants should be supplemented with 400 IU/day [2], although other societies have recommended doses as high as 1,000 IU/day in this population, and dosing recommendations range from 200 to 1,000 IU/day in preterm infants [26-28].

\section{Vitamin D and the Developing Brain}

The effect of vitamin D on neuronal development was initially demonstrated clinically through cases of severe deficiency, with later animal research confirming that infants born to vitamin D-deficient mothers demonstrate thinner cortices and alterations in the size of the lateral ventricles, suggesting a disruption in brain structure. Studies of rat brains have identified increased expression of VDRs in neuroproliferative zones [30]. Additionally, the vitamin $\mathrm{D}$-deficient infants have a greater brain mass than pups born to vitamin $\mathrm{D}$-sufficient mothers, indicating impairment of appropriate neuronal pruning [13]. These alterations in ventricular size have been found to persist into adulthood, even after beginning a diet supplemented with vitamin $\mathrm{D}$ at birth [31]. While vitamin D deficiency has severe consequences during pregnancy, these may differ depending on the period of gestation. For instance, deficiency early in pregnancy is more likely to affect brain structure during the period of organogenesis whereas the pruning of neuronal cells occurs later in gestation, so later deficiency would likely present with differences in brain size. This theory is difficult to prove in murine models, however, due to their relatively short gestational period of 20-22 days and the vitamin D half-life of $2-3$ weeks in these animals [13].

\section{Proapoptotic Effects}

A balance between cellular proliferation and apoptosis is important for proper fetal neural development, and vitamin D is critical to achieving this balance. There are several proposed mechanisms of vitamin D's effect on the apoptosis of neuronal cells (Fig. 2).

In normal neurodevelopment, high levels of cellular proliferation occur early in gestation. As development progresses, the body begins the process of pruning unnecessary cells and neuronal connections. Shifting the balance of apoptosis and mitosis leads to an abnormal number of cells, and disrupts normal brain development by altering the connections between adjacent neurons or neurons and glial cells [32]. While vitamin D may act to prevent neuronal death, as discussed above, it has also been shown to promote apoptosis. Treating glioma cells with calcitriol can lead to an increased expression of proteins including $\mathrm{p} 53$, gadd45, and c-myc [33], resulting in increased programmed cell death. In a study of rats, vitamin D-deficient mothers produced pups whose brains demonstrated lower levels of apoptosis and higher levels of mitosis [32]. These proapoptotic effects appear to be concentration-dependent. At least in vitro, high doses of calcitriol increase apoptosis, while lower doses are antiapoptotic [12].

\section{Vitamin D and the Injured Brain}

As demonstrated in Figure 2, the proapoptotic effects of vitamin $\mathrm{D}$ that support neuronal pruning in normal neurologic development are accompanied by antiapop- 


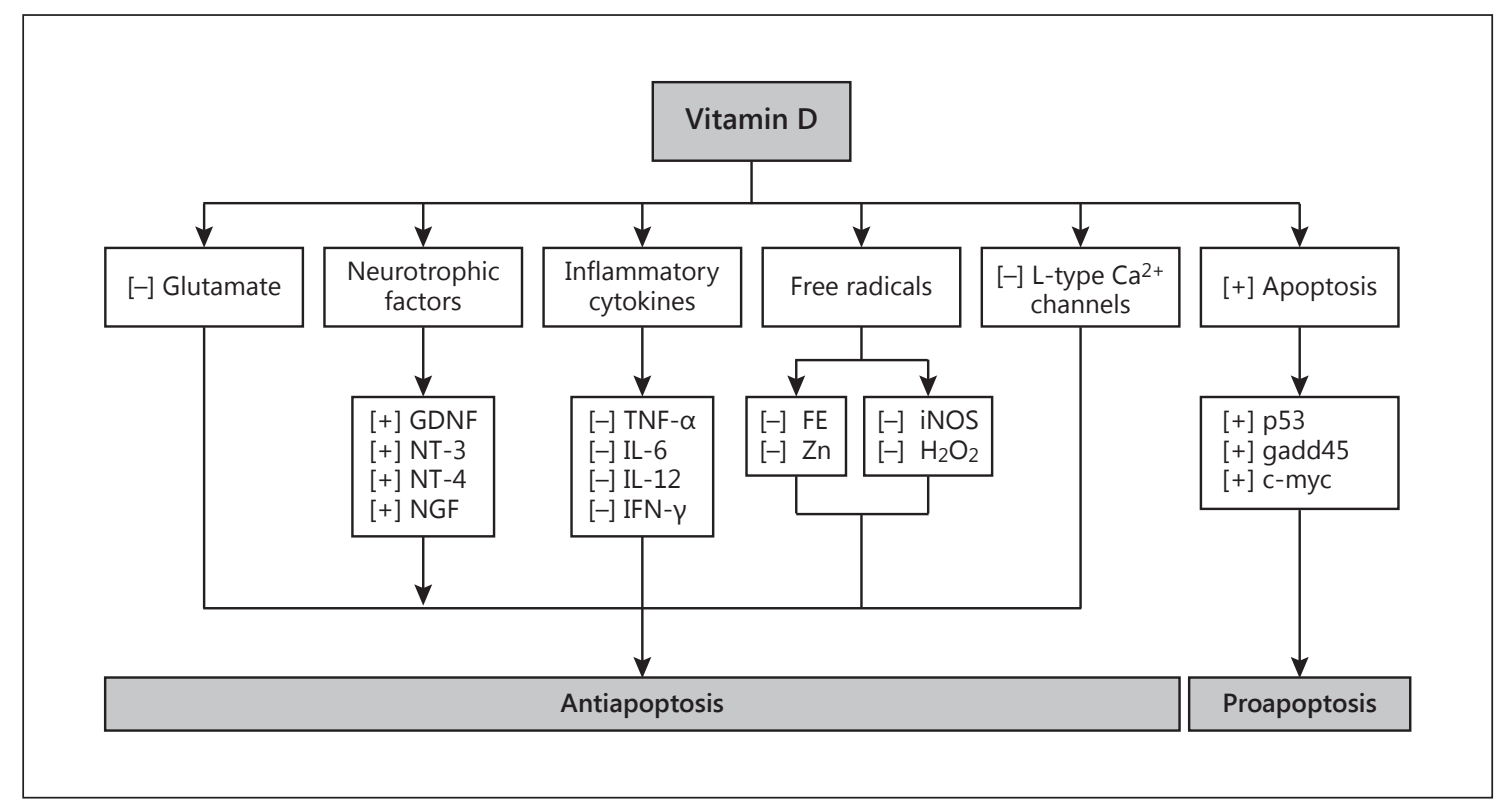

Fig. 2. Pro- and antiapoptotic effects of vitamin D.

totic effects that aid in the prevention of cellular death after neuronal injury. The proposed mechanisms for these neuroprotective actions of vitamin D are summarized below.

\section{Neurotrophic Factors}

The binding of vitamin $\mathrm{D}$ to its receptor activates a cellular cascade, resulting in the expression of neuroprotective genes [12], including the gene expressing glial cellderived neurotrophic factor (GDNF). GDNF has been shown to be an important neuroprotective factor, and increased levels of GDNF have been demonstrated after treatment with calcitriol in models of oxidative brain injury [34] and autoimmune encephalitis [35]. Treating neuronal cells with calcitriol also increases levels of c-Ret mRNA, a GDNF receptor [36]. Additionally, pups born to vitamin $\mathrm{D}$-deficient dams demonstrate lower levels of GDNF [13]. Administering GDNF before an ischemic event in rats resulted in a lower incidence of infarcts as well as a statistically significantly lower volume and lesser extent of infarction [37]. In a subsequent study utilizing a rat model of cortical infarction, 8 days of calcitriol administration resulted in significantly increased levels of GDNF in the cortex and improvement in cortical injury [38]. Nerve growth factor (NGF) is another neurotrophic factor that is important in neuronal development and the maintenance of mature neurons, and it is affected by the presence of vitamin D [14]. In vitro, calcitriol administra- tion increases levels of both NGF mRNA and NGF as an extracellular protein [14-16]. In the study by Eyles et al. [13] described above, rat pups born to vitamin D-deficient dams also demonstrated lower levels of NGF.

Neurotrophins are a class of proteins that play an important role in the survival and maturation of neurons. Specifically, neurotrophin 4 (NT-4) appears to play an important role in ischemic brain injury. Two weeks after ligation of the middle cerebral artery in rats, there was lower expression of NT-4 in the ischemic hemisphere than in the nonischemic hemisphere [39]. Additionally, mouse models without the gene for NT-4 exhibited larger infarct size after both transient and permanent middle cerebral artery occlusion [40]. Furthermore, treatment with NT-4 significantly reduced the volume of basal ganglia and cortical infarcts in rats exposed to middle cerebral artery occlusion 1 day after injury, though not at later time points [41]. Vitamin D deficiency may result in significantly decreased expression of low-affinity neurotrophin receptors [13].

\section{Calcium Regulation}

Activation of L-type calcium channels produces neuronal apoptosis through intracellular influx of calcium. Administration of calcitriol has been shown to downregulate L-type calcium channels [8] by phosphorylating the intermediate filaments of cells that express the channels [42]. This effect appears to be dose-dependent; at low 
concentrations, calcitriol administration results in the decreased expression of L-type calcium channel mRNA and lower measured current through the channels, resulting in a neuroprotective effect on hippocampal neurons. At higher concentrations, however, no neuroprotective effect has been demonstrated, and an increase in L-type channel current observed, indicating the potential for increased apoptosis [43].

In addition to a direct action on the calcium channels, vitamin $\mathrm{D}$ may also affect calcium through a complex interaction with glutamate. Glutamate receptor-binding activates NMDA receptors, leading to calcium influx and neuronal death. When comparing cells pretreated with vitamin $\mathrm{D}$ or vehicle alone, cells in a vitamin $\mathrm{D}$-rich environment are more likely to survive glutamate-induced injury than those in a vitamin D-poor environment. Additionally, in the 12-24 h after glutamate exposure, the expression of VDR mRNA increases in cells that have been previously exposed to vitamin $\mathrm{D}$ [8]. These findings demonstrate that when vitamin $\mathrm{D}$ is available, cells upregulate VDR production to protect against damage from potential glutamate-mediated cellular insults. The relationship between vitamin $\mathrm{D}_{3}$ and glutamate is lost when cells are treated with a protein synthesis inhibitor, suggesting that the effects may be due to alterations in protein synthesis rather than to direct receptor activation [44].

\section{Free Radical Injury}

The production of free radicals has been implicated in many mechanisms of cellular injury. Calcitriol has been demonstrated to reduce the levels of inducible nitric oxide synthase through inhibiting gene activation in astrocytes and glial cells [45]. Additionally, calcitriol prevents the formation of reactive oxygen species (ROS) and the effects of their donors by affecting the hydrogen peroxide pathway [44]. These effects on free radical suppression are enhanced in the presence of other hormones such as progesterone [46]. Similar to the effect on calcium regulation, the presence of a protein synthesis inhibitor inhibits the effect of calcitriol on ROS formation. As such, it is likely that calcitriol itself is not a scavenger of free radicals, but instead acts by producing free radical-scavenging proteins. Additionally, pretreatment, but not cotreatment, with calcitriol has demonstrated improvement in free radicals, so there may be a necessary delay for these new proteins to be assembled [44].

Lastly, vitamin D may alter free radical formation through the metabolism of metal ions, including iron and zinc. The accumulation of ferric iron in cells leads to ROS formation via the Fenton reaction, causing DNA strand breaks [47]. In the locus ceruleus of rat brains, pretreatment with calcitriol before iron-mediated cellular injury resulted in lower levels of cytochrome $c$ and less lipid peroxidation [34]. Calcitriol has also been shown to protect neuronal cells from injury due to iron-related oxidation. In the treated cells, less iron accumulated intracellularly and there were fewer ROS generated [48]. Zinc has also been proposed to cause cellular injury by causing oxidative stress and the apoptosis of neurons [49]; calcitriol pretreatment similarly protects against such injury, by preventing the lipid peroxidation of cortical cells [50].

\section{Inflammatory Cytokines}

Vitamin D may also affect the balance between proand anti-inflammatory cytokines after injury. Vitamin D deficiency not only creates a lack of anti-inflammatory benefits but may even result in an increased inflammatory response, resulting in secondary injury to neurons [9]. For instance, calcitriol has been shown to downregulate the expression of the proinflammatory cytokines TNF- $\alpha$, IL- 6 , and IFN- $\gamma[10,11]$, in part by preventing the action of Th1 cells that leads to the release of the inflammatory cytokines. At the same time, Treg and Th2 cells that produce anti-inflammatory cytokines are upregulated by the presence of vitamin D [9]. When assessing brain inflammation specifically, mice treated with calcitriol demonstrated increased levels of anti-inflammatory IL-4 and TGF- $\beta 1$ [51]. Conversely, in a model of bacterial infection, the microglial cells of vitamin $\mathrm{D}$-deficient mice were actually found to produce less TNF- $\alpha$ and IL-6 [52], suggesting that deficiency also impairs the appropriate inflammatory response during acute infections. While vitamin D has been shown to alter cytokine levels, the reverse may also be true. In human brain pericytes exposed to TNF- $\alpha$ and IFN- $\gamma$, upregulation of CYP27B1 occurred, a gene involved in the synthetic pathway of $1,25-(\mathrm{OH})_{2} \mathrm{D}_{3}$ [53].

\section{Timing of Vitamin D Administration in Relation to Injury}

There are conflicting data as to whether vitamin D supplementation before injury provides significant neuroprotection. In rats, 8 days of calcitriol supplementation before ischemic brain injury resulted in significantly lower infarct volumes, but no neuroprotective effect was seen in the group receiving supplementation for only 4 days before injury [38]. Another study demonstrated that 8 days of pretreatment with calcitriol did not significantly decrease markers of cerebral damage in a rat ischemiareperfusion model, although supplementation with both 
calcitriol and a vitamin $\mathrm{C}$ supplement did result in decreased ROS [54]. In vitro, administering calcitriol $24 \mathrm{~h}$ before a glutamate-induced injury was protective of rat cerebellar cells, with no effect seen in the group given the same treatment after injury [12].

Studies examining vitamin D administration after injury have also been conflicting. In a rat stroke model, there was no neuroprotection observed after 5 days of vitamin D treatment after injury [55]; however, adult human studies have shown vitamin $\mathrm{D}$ supplementation after stroke decreased mortality, disability, and stroke symptoms [56, 57]. When assessing neonatal brain injury, a study utilizing a rat model of HIE administered calcitriol $30 \mathrm{~min}$ after injury, and demonstrated smaller brain lesions in the treated group than in the untreated group. An additional group was given 7 days of calcitriol treatment, which resulted in a slightly greater reduction in the size of the brain lesions, but the difference between the 2 calcitriol groups was small [12].

\section{Severity of Injury}

While there appears to be an association between low vitamin $\mathrm{D}$ levels and the severity of HIE, the precise interaction remains unclear. In infants with HIE, both the infants and their mothers have been found to have decreased levels of vitamin D [18]. One study demonstrated that at the time of NICU admission, 70\% of infants with hypoxic-ischemic brain injury were considered to be vitamin D-deficient, and many of these infants continued to have declining levels for $72 \mathrm{~h}$ after the injury despite the administration of parenteral nutrition containing vitamin $\mathrm{D}_{2}$ supplementation of about $400 \mathrm{IU} /$ day. The same study showed that the vitamin D level was not an independent factor for survival, and there was no significant improvement in functional outcome with vitamin $\mathrm{D}$ supplementation [19], although the dosage may not have been high enough to show significant improvement. It is unclear whether this decline in vitamin $\mathrm{D}$ level is due to the utilization of existing vitamin D stores or an attempt to minimize the effects of initial injury and further damage from a secondary inflammatory response. To date, no study has been adequately powered to show an association between the level of injury or functional outcome with vitamin D status at birth or due to supplementation.

\section{Conclusion}

Vitamin D is a vital component of normal neuronal development, but may also play an important role in the brain's response to injury in the neonatal period. Vitamin $\mathrm{D}$ deficiency has been linked to both abnormal brain development and increased vulnerability to neurologic injury. Treatment with vitamin $\mathrm{D}$ has resulted in the reduced size and severity of brain infarcts, but many of the studies on its role in the central nervous system are either performed on animal models or adult humans. To better understand the efficacy of vitamin D in altering HIE outcomes, it is necessary to conduct further clinical research in the neonatal population. Important questions to address include establishing the role of maternal vitamin D supplementation in the prevention of HIE and the dosing required for adequate neuroprotection, although both questions will face the issue of obtaining adequate sample sizes in clinical studies due to the relative rarity of neonatal HIE. Multicenter trials will therefore be critical, as vitamin D has significant (though still mostly theoretical) potential for preventing or reducing long-term neurologic injury due to neonatal HIE.

\section{Disclosure Statement}

The authors declare no conflicts of interest.

\section{References}

1 Kumar J, Muntner P, Kaskel F, Hailpern S, Melamed M: Prevalence and Associations of 25-Hydroxyvitamin D Deficiency in US Children: NHANES 2001-2004. Pediatrics 2009; 124:e362-e370.

2 Wagner C, Greer F; American Academy of Pediatrics Section on Breastfeeding; American Academy of Pediatrics Committee on Nutrition: Prevention of rickets and vitamin $D$ deficiency in infants, children, and adolescents. Pediatrics 2008;122:1142-1152.
3 Hanson C, Armas L, Lyden E, Anderson-Berry A: Vitamin $D$ status and associations in newborn formula-fed infants during initial hospitalization. J Am Diet Assoc 2011;111: 1836-1843.

4 Saraf R, Morton S, Camargo C, Grant C: Global summary of maternal and newborn vitamin D status - a systematic review. Matern Child Nutr 2016;12:647-668.
5 Fouda MA, Turkestani IZ, Almusharraf S, AlAjlan A, Angkaya-Bagayawa FF, Sabico S, Mohammed AG, Hassanato R, Al-Serehi A, Alshingetti NM, Al-Daghri NM: Extremely high prevalence of maternal and neonatal vitamin D deficiency in the Arab population. Neonatology 2017;112:225-230.

6 Zehnder D, Bland R, Williams M, McNinch R, Howie A, Stewart P, Hewison M: Extrarenal expression of 25-hydroxyvitamin $\mathrm{D}_{3}-1 \alpha$ hydroxylase. J Clin Endocrinol Metab 2001; 86:888-894. 
7 Eyles D, Smith S, Kinobe R, Hewison M, McGrath J: Distribution of the vitamin D receptor and 1a-hydroxylase in human brain. J Chem Neuroanat 2005;29:21-30.

8 Taniura H, Ito M, Sanada N, Kuramoto N, Ohno Y, Nakamichi N, Yoneda Y: Chronic vitamin $\mathrm{D}_{3}$ treatment protects against neurotoxicity by glutamate in association with upregulation of vitamin $\mathrm{D}$ receptor mRNA expression in cultured rat cortical neurons. J Neurosci Res 2006;83:1179-1189.

9 Alfieri D, Lehmann M, Oliveira S, Flauzino T, Delongui F, Araújo M, Dichi I, Delfino V, Mezzaroba L, Simão A, Reiche E: Vitamin D deficiency is associated with acute ischemic stroke, C-reactive protein, and short-term outcome. Metab Brain Dis 2017;32:493-502.

10 Zhang Y, Leung D, Richers B, Liu Y, Remigio L, Riches D, Goleva E: Vitamin D inhibits monocyte/macrophage proinflammatory cytokine production by targeting MAPK phosphatase-1. J Immunol 2012;188:2127-2135.

11 Penna G, Roncari A, Amuchastegui S, Daniel K, Berti E, Colonna M, Adorini L: Expression of the inhibitory receptor ILT3 on dendritic cells is dispensable for induction of CD4+Foxp3+ regulatory T cells by 1,25-dihydroxyvitamin $\mathrm{D}_{3}$. Blood 2005; 106:3490-3497.

12 Kajta M, Makarewicz D, Ziemińska E, Janta D, Domin H, Lasoń W, Kutner A, Łazarewicz $\mathrm{J}$ : Neuroprotection by co-treatment and posttreating with calcitriol following the ischemic and excitotoxic insult in vivo and in vitro. Neurochem Int 2009;55:265-274.

13 Eyles D, Brown J, Mackay-Sim A, McGrath J, Feron F: Vitamin $\mathrm{D}_{3}$ and brain development. Neuroscience 2003;118:641-653.

14 Wion D, MacGrogan D, Neveu I, Jehan F, Houlgatte R, Brachet P: 1,25-dihydroxyvita$\min \mathrm{D}_{3}$ is a potent inducer of nerve growth factor synthesis. J Neurosci Res 1991;28:110114.

15 Neveu I, Naveilhan P, Jehan F, Baudet C, Wion D, De Luca H, Brachet P: 1,25-Dihydroxyvitamin $\mathrm{D}_{3}$ regulates the synthesis of nerve growth factor in primary cultures of glial cells. Brain Res Mol Brain Res 1994;24: 70-76.

16 Cornet A, Baudet C, Neveu I, Baron-Van Evercooren A, Brachet P, Naveilhan P: 1,25-Dihydroxyvitamin $\mathrm{D}_{3}$ regulates the expression of VDR and NGF gene in Schwann Cells in vitro. J Neurosci Res 1998;53:742746.

17 Kurinczuk J, White-Koning M, Badawi N: Epidemiology of neonatal encephalopathy and hypoxic-ischaemic encephalopathy. Early Hum Dev 2010;86:329-338.

18 Mutlu M, Sariaydin M, Aslan Y, Kader Ş, Dereci S, Kart C, Özer Yaman S, Kural B: Status of vitamin $\mathrm{D}$, antioxidant enzymes, and antioxidant substances in neonates with neonatal hypoxic-ischemic encephalopathy. J Matern Fetal Neonatal Med 2016;29:2259-2263.
19 Lowe D, Hollis B, Wagner C, Bass T, Kaufman D, Horgan M, Givelichian L, Sankaran K, Yager J, Katikaneni L, Wiest D, Jenkins D: Vitamin D insufficiency in neonatal hypoxicischemic encephalopathy. Pediatr Res 2017; 82:55-62.

20 Heaney R, Recker R, Grote J, Horst R, Armas $\mathrm{L}$ : Vitamin $\mathrm{D}_{3}$ is more potent than vitamin $\mathrm{D}_{2}$ in humans. J Clin Endocrinol Metab 2011; 96:E447-E452.

21 Trang H, Cole D, Rubin L, Pierratos A, Siu S, Vieth R: Evidence that vitamin $\mathrm{D}_{3}$ increases serum 25-hydroxyvitamin D more efficiently than does vitamin $\mathrm{D}_{2}$. Am J Clin Nutr 1998; 68:854-858.

22 Hollis B, Lowery J, Pittard III W, Guy D, Hansen J: Effect of age on the intestinal absorption of vitamin $\mathrm{D}_{3}$-palmitate and nonesterified vitamin $\mathrm{D}_{2}$ in the term human infant. J Clin Endocrinol Metab 1996;81:1385-1388.

23 Chabas J, Stephan D, Marqueste T, Garcia S, Lavaut M, Nguyen C, Legre R, Khrestchatisky M, Decherchi P, Feron F: Cholecalciferol (vitamin $D_{3}$ ) improves myelination and recovery after nerve injury. PLoS One 2013;8: E65034.

24 Siafarikas A, Piazena H, Feister U, Bulsara M, Meffert H, Hesse V: Randomised controlled trial analysing supplementation with 250 versus 500 units of vitamin $D_{3}$, sun exposure and surrounding factors in breastfed infants. Arch Dis Child 2011;96:91-95.

25 Gallo S, Comeau K, Vanstone C, Agellon S, Sharma A, Jones G, L'Abbé M, Khamessan A, Rodd C, Weiler H: Effect of different dosages of oral vitamin $\mathrm{D}$ supplementation on vitamin D status in healthy, breastfed infants: a randomized trial. JAMA 2013;309:17851792.

26 Abrams S: Calcium and vitamin D requirements of enterally fed preterm infants. Pediatrics 2013;131:e1676-e1683.

27 Agostoni C, Buonocore G, Carnielli VP, De Curtis M, Darmaun D, Decsi T, et al; ESPGHAN Committee on Nutrition: Enteral Nutrient supply for preterm infants: commentary from the European Society of Paediatric Gastroenterology, Hepatology and Nutrition Committee on Nutrition. J Pediatr Gastroenterol Nutr 2010;50:85-91.

28 Holick MF, Binkley NC, Bischoff-Ferrari HA, Gordon CM, Hanley DA, Heaney RP, Murad $\mathrm{MH}$, Weaver CM; Endocrine Society: Evaluation, treatment, and prevention of vitamin $\mathrm{D}$ deficiency: an Endocrine Society clinical practice guideline. J Clin Endocrinol Metab 2011;96:1911-1930.

29 Walker V, Zhang X, Rastegar I, Liu P, Hollis B, Adams J, Modlin R: Cord blood vitamin D status impacts innate immune responses. J Clin Endocrinol Metab 2011;96:1835-1843.

30 Cui X, McGrath J, Burne T, Mackay-Sim A, Eyles D: Maternal vitamin D depletion alters neurogenesis in the developing rat brain. Int J Dev Neurosci 2007;25:227-232.
31 Féron F, Burne TH, Brown J, Smith E, McGrath JJ, Mackay-Sim A, Eyles DW: Developmental vitamin $\mathrm{D}_{3}$ deficiency alters the adult rat brain. Brain Res Bull 2005;65:141-148.

32 Ko P, Brukert R, McGrath J, Eyles D: Maternal vitamin $\mathrm{D}_{3}$ deprivation and the regulation of apoptosis and cell cycle during rat brain development. Brain Res Dev Brain Res 2004; 153:61-68.

33 Baudet C, Chevalier G, Chassevent A, Canova C, Filmon R, Larra F, Brachet P, Wion D: 1,25-Dihydroxyvitamin $\mathrm{D}_{3}$ induces programmed cell death in a rat glioma cell line. J Neurosci Res 1996;46:540-550.

34 Chen KB, Lin AM, Chiu TH: Systemic vitamin $D_{3}$-attenuated oxidative injuries in the locus coeruleus of rat brain. Ann NY Acad Sci 2003;993:313-324.

35 Shirazi HA, Rasouli J, Ciric B, Rostami A, Zhang GX: 1,25-Dihydroxyvitamin $\mathrm{D}_{3}$ enhances neural stem cell proliferation and oligodendrocyte differentiation. Exp Mol Pathol 2015;98:240-245.

36 Pertile RA, Cui X, Hammond L, Eyles DW: Vitamin D regulation of GDNF/Ret signaling in dopaminergic neurons. FASEB J 2017, Epub ahead of print.

37 Wang Y, Lin SZ, Chiou AL, Williams L, Hoffer B: Glial cell line-derived neurotrophic factor protects against ischemia-induced injury in the cerebral cortex. J Neurosci 1997;17:4341-4348.

38 Wang Y, Chiang YH, Su TP, Hayashi T, Morales M, Hoffer BJ, Lin SZ: Vitamin $\mathrm{D}_{3}$ attenuates cortical infarction induced by middle cerebral arterial ligation in rats. Neuropharmacology 2000;39:873-880.

39 Chung JY, Kim MW, Bang MS, Kim M: Increased expression of neurotrophin 4 following focal cerebral ischemia in adult rat brain with treadmill exercise. PLoS One 2013;8: e52461.

40 Endres M, Fan G, Hirt L, Fujii M, Matsushita K, Liu X, Jaenisch R, Moskowitz M: Ischemic brain damage in mice after selectively modifying BDNF or NT4 gene expression. J Cereb Blood Flow Metab 2000;20:139-144.

41 Chan KM, Lam DT, Pong K, Widmer H, Hefti F: Neurotrophin-4/5 treatment reduces infarct size in rats with middle cerebral artery occlusion. Neurochem Res 1996;21:763-767.

42 Zanatta L, Goulat PB, Gonçalves R, Pierozan P, Winkelmann-Duarte E, Woehl VM, Pessoa-Pureur R, Meno Barreto Silva, Fátima Regina, Zamoner A: 1a, 25-Dihydroxyvitamin $\mathrm{D}_{3}$ mechanism of action: modulation of $\mathrm{L}$ type calcium channels leading to calcium uptake and intermediate filament phosphorylation in cerebral cortex of young rats. Biochim Biophys Acta 2012;1823:1708-1719.

43 Brewer L, Thibault V, Chen K, Langub M, Landfield P, Porter N: Vitamin D hormone confers neuroprotection in parallel with downregulation of L-type calcium channel expression in hippocampal neurons. J Neurosci 2001;21:98-108. 
44 Ibi M, Sawada H, Nakanishi M, Kume T, Katsuki H, Kaneko S, Shimohama S, Akaike A: Protective effects of $1 \alpha, 25-(\mathrm{OH})_{2} \mathrm{D}_{3}$ against the neurotoxicity of glutamate and reactive oxygen species in mesencephalic cultures. Neuropharmacology 2001;40:761-771.

45 Garcion E, Nataf S, Berod A, Darcy F, Brachet P: 1,25-Dihydroxyvitamin $\mathrm{D}_{3}$ inhibits the expression of inducible nitric oxide synthase in rat central nervous system during experimental allergic encephalomyelitis. Mol Brain Res 1997;45:225-267.

46 Tang H, Hua F, Wang J, Yousuf S, Atif F, Sayeed I, Stein D: Progesterone and vitamin D combination therapy modulates inflammatory response after traumatic brain injury. Brain INJ 2015;29:1165-1174.

47 Mello-Filho A, Meneghini R: Iron is the intracellular metal involved in the production of DNA damage by oxygen radicals. Mutat Res 1991;251:109-113.

48 Uberti F, Morsanuto V, Bardelli C, Molinari C: Protective effects of 1a,25-Dihydroxyvitamin $\mathrm{D}_{3}$ on cultured neural cells exposed to catalytic iron. Physiol Rep 2016;4:e12769.
49 Lin A, Fan SF, Yang DM, Hsu LL, Yang CHJ: Zinc-induced apoptosis in substantia nigra of rat brain: neuroprotection by vitamin $\mathrm{D}_{3}$. Free Radic Biol Med 2003;34:1416-1425.

50 Lin A, Chen KB, Chao PL: Antioxidative effect of vitamin $\mathrm{D}_{3}$ on zinc-induced oxidative stress in CNS. Ann NY Acad Sci 2005; 1053 : 319-329.

51 Catorna MT, Woodward WD, Hayes CE, DeLuca HF: 1,25-Dihydroxyvitamin $\mathrm{D}_{3}$ is a positive regulator for the two anti-encephalitogenic cytokines TGF- $\beta 1$ and IL-4. J Immunol 1998;160:5314-5319.

52 Djukic M, Onken ML, Schütze S, Redlich S, Götz A, Hanisch U, Bertsch T, Ribes S, Hanenberg A, Schneider S, Bollheimer C, Sieber C, Nau R: Vitamin D deficiency reduces the immune response, phagocytosis rate, and intracellular killing rate of microglial cells. Infect Immun 2014;82:2585-2594.
53 Nissou MF, Guttin A, Zenga C, Berger F, Issartel JP, Wion D: Additional clues for a protective role of vitamin $\mathrm{D}$ in neurodegenerative diseases: 1,25-dihydroxyvitamin $\mathrm{D}_{3}$ triggers an anti-inflammatory response in brain pericytes. J Alzheimers Dis 2014;42:789-799.

54 Ekici F, Ozyurt B, Erdogan H: The combination of vitamin $\mathrm{D}_{3}$ and dehydroascorbic acid administration attenuates brain damage in focal ischemia. Neurol Sci 2009;30:207-212.

55 Balden R, Selvamani A, Sohrabji F: Vitamin D deficiency exacerbates experimental stroke injury and dysregulates ischemia-induced inflammation in adult rats. Endocrinology 2012;153:2420-2435.

56 Gupta A, Prabhakar S, Modi M, Bhadada S, Kalaivani M, Lal V, Khurana D: Effect of Vitamin D and calcium supplementation on ischaemic stroke outcome: a randomised controlled open-label trial. Int J Clin Pract 2016; 70:764-770.

57 Narasimhan S: Role of vitamin D in the outcome of ischemic stroke - a randomized controlled trial. J Clin Diagn Res 2017;11:CC06CC10. 